\title{
CHARACTERISTICS OF THE NORMAL ELECTROENCEPHALOGRAM. \\ III. THE EFFECT OF VARYING BLOOD SUGAR LEVELS ON THE OCCIPITAL CORTICAL POTENTIALS IN ADULTS DURING HYPERVENTILATION 1
}

\author{
BY MARY A. B. BRAZIER, JACOB E. FINESINGER, AND ROBERT S. SCHWAB \\ (From the Department of Neuropsychiatry, Harvard Medical School, and the Psychiatric Department \\ and Electroencephalographic Laboratory, Massachusetts General Hospital, Boston)
}

(Received for publication August 2, 1943)

Delta activity, i.e., waves of a frequency slower than 5 per second, is not a normal finding in the electroencephalograms of adults when they are fully awake and breathing quietly (1). This type of slow activity is found in some pathological states, but there are certain physiological factors which will cause it to appear in the record of the normal adult. The purpose of the present study was to investigate the effect of hyperventilation upon the occipital cortical potentials in a series of 45 normal subjects (29 males, 16 females), at varying blood sugar levels. The technique for the following experiments has been fully described in a previous paper (2).

If the blood sugar is lowered in normal sub-

1 This study was aided by a grant from the Harrington Fund. jects, delta waves will appear in the third minute of hyperventilation in nearly all cases. An example of one such case (female, age 21) is shown in Figure 1. This figure demonstrates clearly that in this subject, the brain wave pattern is a typical alpha type, stable at fasting blood sugar levels, where it is, in fact, identical with the tracing obtained at the higher level after the ingestion of glucose. Only at the artificially low blood sugar level of $50 \mathrm{mgm}$. per $100 \mathrm{cc}$. is the brain wave abnormal with trains of high voltage delta waves. All the tracings in this illustration (Figure 1) were taken during the third minute of hyperventilation.

Great individual variation was found within the group of 45 normals as to the level at which delta waves could be made to appear by hyper-

\section{BLOOD SUGAR 98 MGM}

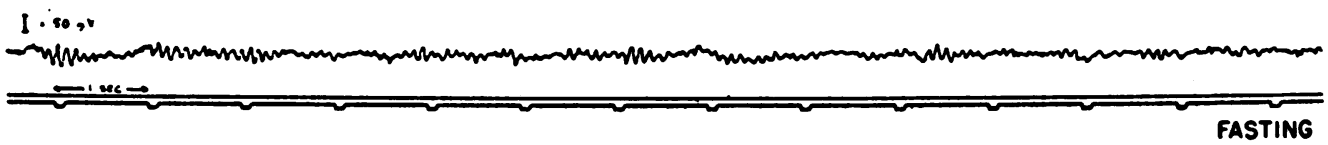

BLOOD SUGAR 50 MGM

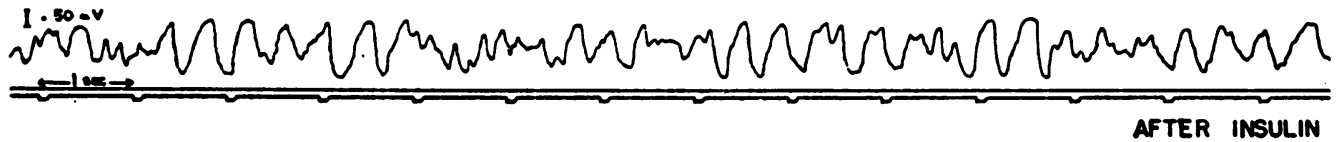

BLOOD SUGAR 125 MGM

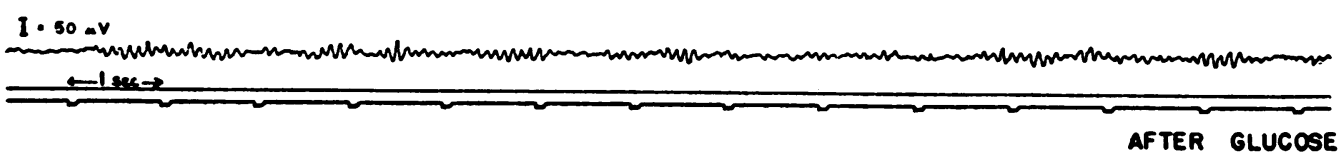

Fig. 1. Delta Activity in a Normal Adult, Produced by Hyperventilation at Low Blood Sugar Levels

Three tracings from the same individual during hyperventilation at different blood sugar levels. 
ventilation. In some (13 per cent of this series), they could not be elicited, even by lowering the blood sugar to $40 \mathrm{mgm}$. with insulin, whereas in a few (4 per cent), they were present at all levels, even after the ingestion of glucose.

The arbitrary criterion taken was the appearance of delta waves during at least 5 per cent of the third minute of hyperventilation (i.e., for at least 3 seconds). At blood sugar levels higher than $70 \mathrm{mgm}$. per $100 \mathrm{cc}$., 31 subjects $(69$ per cent of the total series) were found to give at least this amount of delta activity.

Of these 31 subjects, 17 (38 per cent of the total series) still gave delta waves when the blood sugar level was raised to $100 \mathrm{mgm}$.; 5 subjects (11 per cent of the total) gave this amount of delta waves when the blood sugar level was as high as $130 \mathrm{mgm}$.

The clinical importance of these findings is their demonstration of the fact that, in the interpretation of brain wave records, delta waves in the third minute of hyperventilation cannot be regarded as an abnormal finding, since they occur in 38 per cent of normal adults at non-fasting blood sugar levels $(100 \mathrm{mgm}$. or over). The importance of controlling the blood sugar level has also been stressed by Davis and Wallace $(3,4)$ as a result of their experiments on controlled hyperventilation of normals.

If the subject is given glucose by mouth before the test, or is examined within one-half hour of a meal in order to ensure a blood sugar of over $130 \mathrm{mgm}$., the number of normals giving delta waves falls to 11 per cent, but is still appreciable.

The records were then examined to determine whether the delta activity found in the second minute of overbreathing would be a better differentiating criterion. Seventeen (38 per cent) gave delta waves in the second minute for at least 5 per cent of the time when the blood sugar was kept at or above $70 \mathrm{mgm}$. Of these 17 subjects, 3 ( 7 per cent of the total series) still gave this amount of delta waves in the second minute when the blood sugar was raised to above $100 \mathrm{mgm}$. No one gave delta waves in the second minute when the blood sugar was kept at or above $130 \mathrm{mgm}$.

The same criterion, that is, regarding anything less than 5 per cent delta as negligible, was used in compiling the above figures; they are therefore strictly comparable with the figures for the third minute of overbreathing, and suggest that the differentiating threshold for delta activity should be the second minute of hyperventilation at blood sugar levels of $130 \mathrm{mgm}$. or over. Delta waves appearing for 5 per cent of the time in these circumstances may be regarded as an abnormal finding.

\section{The percentage time delta in the third minute of hyperventilation at various blood sugar levels}

This report has so far dealt with the number of individuals giving delta activity under certain experimental conditions. The next point to be examined is the amount of delta activity induced by the various factors, i.e., the percentage time delta.

One hundred and sixty-one observations on 45 normal subjects were made at different blood sugar levels, and the mean percentage time delta

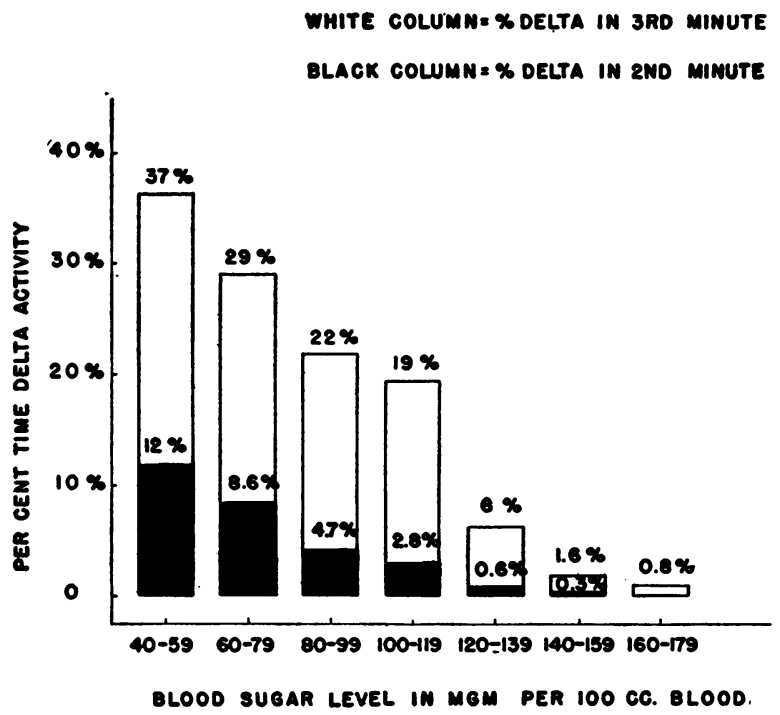

Fig. 2. Percentage Time Delta Activity on HYPERVENTILATION

The above chart shows the percentage time delta activity in the second minute of hyperventilation (black columns), and in the third minute (white columns), in 45 normal adults. Where more than one observation at the same blood sugar level was made for one individual, the maximum amount of delta at this level is the one recorded. The number at the top of each column is the arithmetical mean for the group. The number of observations from which each column was computed were, reading from left to right: $11,28,39,24,31,23$, and 5 . 
in the third minute of hyperventilation was calculated at the various levels. The results are seen in the white columns of Figure 2. These are to be compared with the figures obtained on the same persons in the second minute of overbreathing, which are shown in the blackened portion of the columns in Figure 2. It is clear from this figure that there is a negligible amount of delta activity in the second minute of hyperventilation at non-fasting blood sugar levels.

\section{Dominant frequency and tendency to delta activity on hyperventilation}

The dominant frequency of the majority of waves in the occipital recordings was determined in this series by the distribution curve method, described in a previous paper (1). It was thought that possibly the slower the original rhythm, the more delta activity could be expected, but no significant difference in the amount of delta activity in the third minute of hyperventilation was found between the group with dominant frequencies slower than 10.5 and those with 10.5 cycles and faster. The figures are:

25 normals with dominant frequencies slower than 10.5 mean percentage time

$$
\text { delta }=44.9 \pm 27.8
$$

19 normals with dominant frequencies of $\mathbf{1 0 . 5}$ and faster mean percentage time delta $=36.4 \pm 19.7$

The standard deviations of these means are so large that the difference between the 2 means is not significant. Thus, in this series, the lack of stability of the electroencephalogram to lowered blood sugar and increased ventilation shows no statistically significant relationship with the basic rhythm of the subject.

\section{Depth of hyperventilation and its effect on delta activity}

In addition to blood sugar level, there is another factor at work in determining the amount of delta activity which will occur, and this is the depth of hyperventilation. If the blood sugar level is kept constant, the amount of delta activity appearing in the third minute of hyperventilation will be significantly greater if the average respiratory volume during each of the 3 minutes of overbreathing is over $600 \mathrm{cc}$. per $\mathrm{kgm}$. body weight, than if it is below this figure. Taking, as an example, the blood sugar range 80 to $99 \mathrm{mgm}$., there were 31 readings on subjects who breathed under $600 \mathrm{cc}$. per kilogram body weight in each of the 3 minutes of hyperventilation, and 18 readings on subjects who breathed over this amount. The mean percentage time delta in the third minute of hyperventilation for each of the two groups is shown below:

Under $600 \mathrm{cc}$. per $\mathrm{kgm}$. body weight per minute ....Mean percentage time delta 10 per cent

Over $600 \mathrm{cc}$. per kgm. body weight per minute ....Mean percentage time delta 20 per cent

These figures reveal that there is an average of twice as much delta activity with the deeper level of breathing when the blood sugar is kept constant.

In 13 subjects, more than one observation was obtained at a blood sugar level between 80 and 99 mgm., but at different depths of hyperventilation. The results are given in Table $I$ as the percentage time delta in the third minute of hyperventilation. The figures show clearly the influence of the greater depth of breathing upon delta activity, for the percentage time delta in the third minute is greater when the mean ventilation for the 3 minutes is increased.

\section{The effect of age on the stability of the electroen-} cephalogram during hyperventilation

A study of age relations was made in this series, although the age range was a very narrow one (17 to 38 ). It revealed that the breakdown into delta activity in the third minute of hyperventilation occurred more readily, i.e., at higher blood sugar levels, in the younger members of the group. Examining once again the different groups which gave delta at widely different blood sugar levels, the following mean age for each group was found: (The results are given in order of decreasing stability)

2 subjects gave no delta at any

level

mean age 30 
TABLE I

Percentage time delta in the third minute of hyperventilation at different depths of breathing,

Mean depth of ventilation in the 3 minutes of hyperventilation (per kgm. body weight)

\begin{tabular}{|c|c|c|c|c|c|c|}
\hline Subject & Under $500 \mathrm{cc}$. & $500 \mathrm{cc}$. & Between 500 and 600 & $600 \mathrm{cc}$. & Between 600 and 700 & $700 \mathrm{cc}$. and over \\
\hline $\begin{array}{r}5 \\
10 \\
13 \\
15 \\
18 \\
26 \\
27 \\
28 \\
29 \\
35 \\
40 \\
43 \\
44\end{array}$ & 49 & 61 & $\begin{array}{r}16 \\
6 \\
8 \\
10 \\
0 \\
0 \\
31\end{array}$ & $\begin{array}{r}18 \\
30 \\
2 \\
11 \\
4 \\
4 \\
24 \\
13 \\
73\end{array}$ & $\begin{array}{l}41 \\
13 \\
10 \\
84 \\
40\end{array}$ & 35 \\
\hline
\end{tabular}

14 subjects gave delta only when the blood sugar was below $70 \mathrm{mgm}$.

17 subjects still gave delta when the blood sugar was above $100 \mathrm{mgm}$.

mean age 25

mean age 22

These groups are too small, and the age range too narrow for a statistical presentation of the age effect, but it would appear that the stability of the cortical potentials to hyperventilation increases with increasing age.

\section{DISCUSSION}

The appearance of high voltage slow waves as a result of voluntary hyperventilation is well known. This has been shown by Lennox and Gibbs $(5,6)$ to be due to increase in the carbon dioxide tension of the arterial blood reaching the brain, and not to anoxia, secondary to vasoconstriction. Berger (7) showed that slow waves can also be elicited by anoxia induced by rebreathing respired air from which the carbon dioxide has been removed; this has been confirmed by Gibbs and Davis (8) in human subjects breathing pure nitrogen, but the anoxemia has to be severe before any significant slowing takes place (Gibbs (9)). Himwich (10) has demonstrated an inverse relationship between oxygen utilization by the brain and delta frequency.

In the present paper, a study has been made of the interplay of the two factors: the influence of decreased carbon dioxide tension of the blood produced by varying depths of ventilation, and the anoxic effect on the cortex of lowering the sugar content of the blood.

\section{SUMMARY}

(1) Delta activity in the third minute of hyperventilation is not diagnostic of abnormality, since it occurs in 38 per cent of normals at non-fasting blood sugar levels. If the blood sugar level be raised above $130 \mathrm{mgm} ., 11$ per cent of normals still give delta activity in the third minute.

(2) A better differentiation is given by the second minute of hyperventilation, since only 7 per cent of normals give delta activity at nonfasting blood sugar levels, and none above $130 \mathrm{mgm}$.

(3) The percentage time delta in normals varies inversely with the blood sugar level, in both the second and third minutes of hyperventilation.

(4) The tendency of an individual to produce delta activity on hyperventilation is not related to the basic dominant frequency of his resting record.

(5) When the blood sugar level is kept constant, the deciding factor in determining the amount of delta activity induced by hyperventilation is the depth of breathing during the 3-minute period.

(6) There is some evidence that at lower age levels in the adult, the electroencephalogram is 
less stable to change in blood sugar and ventilation level.

For technical assistance in this work, the authors are indebted to Miss Margaret Gray and Mrs. Frances Cooperstein.

\section{BIBLIOGRAPHY}

1. Brazier, M. A. B., and Finesinger, J. E., The characteristics of the normal electroencephalogram. I. A study of the occipital cortical potentials in 500 normal adults. J. Clin. Invest., 1944, 23, 303.

2. Brazier, M. A. B., Finesinger, J. E., and Schwab, R. S., The characteristics of the normal electroencephalogram. II. The effect of varying blood sugar levels on the occipital cortical potentials in adults during quiet breathing. J. Clin. Invest., 1944, 23, 313.

3. Davis, H., and Wallace, W. McL., Factors affecting the encephalographic changes induced by hyperventilation. Am. J. Physiol., 1941, 133, P 258.

4. Davis, H., and Wallace, W. McL., Factors affecting changes produced in electroencephalogram by standardized hyperventilation. Arch. Neurol. and Psychiat., 1942, 47, 606.

5. Lennox, W. G., Gibbs, F. A., and Gibbs, E. L., The relationship in man of cerebral activity to blood flow and blood constituents. J. Neurol. and Psychiat., 1938, 1, 211.

6. Gibbs, E. L., Gibbs, F. A., Lennox, W. G., and Nims, L. F., Regulation of cerebral carbon dioxide. Arch. Neurol. and Psychiat., 1942, 47, 879.

7. Berger, H., Über das Elektrenkephalogramm des Menschen. IX. Arch. f. Psychiat., 1934, 102, 538.

8. Gibbs, F. A., and Davis, H., Changes in the human electroencephalogram associated with loss of consciousness. Am. J. Physiol., 1935, 113, 49.

9. Gibbs, F. A., Williams, D., and Gibbs, E. L., Modification of the cortical frequency spectrum by changes in $\mathrm{CO}_{2}$, blood sugar and $\mathrm{O}_{2}$. J. Neurophysiol., 1940, $3,49$.

10. Himwich, H. E., Hadidian, Z., Fazekas, J. F., and Hoagland, H., Cerebral metabolism and electrical activity during insulin hypoglycemia in man. Am. J. Physiol., 1939, 125, 578. 